\title{
EXPLORING THE EMOTIONS OF DISTANCE LEARNING STUDENTS IN AN ASSESSED, ONLINE, COLLABORATIVE PROJECT
}

\author{
Jake Hilliard, Karen Kear, Helen Donelan, Caroline Heaney, The Open University, United
}

Kingdom

\section{Summary}

Previous research has highlighted the importance of emotions of learners in online learning settings. However, much of this research has tended to focus on individual learning situations rather than social learning activities. The exploration of the emotional experiences of distance learners has also received little attention when compared to other student groups (e.g. fulltime or blended learning students). As many distance learners are in full- or part-time employment or have other commitments, the emotions experienced and the reasons for these emotions might be greatly different to other student populations. This study investigated these issues by exploring the emotional experiences of distance learners when undertaking an assessed, online, collaborative group project. Self-report data about the emotions experienced and their causes were gathered using a structured diary at six times points during the group activity. Findings revealed that learners experienced a ranged of pleasant and unpleasant emotions before, during and after the collaborative activity. Feelings of satisfaction and relief were the most reported pleasant emotions and feelings of anxiety and frustration were the most frequently reported unpleasant emotions. To conclude this paper, implications for educators are briefly discussed and reflections on using an online diary to explore student emotions are provided.

\section{Introduction}

The UK Open University (OU) is currently one the largest Higher Education (HE) institutions in Europe, with a student population of around 120,000 (Higher Education Student Statistics, 2019). The OU is based on a unique distance education method called "Supported Open Learning". This method offers a flexible approach to education, with students having much greater freedom to study where and when they like, compared to traditional campus based universities. OU students come from diverse backgrounds; for instance, their age (OU students are typically older than those who attend typical HE institutions); location (located all over the UK and around the world); previous levels of education (the OU require no formal entry qualifications); and employment status (many OU students are in full-time or part-time employment) will vary greatly. Additionally, there are a higher portion of students with disabilities and with additional needs/requirements studying at the OU in comparison to other UK universities (The Open University, 2018). Flexibility is 
therefore central to underpinning the OU's mission of being open, and is essential for learners studying at the OU.

To deliver Supported Open Learning, the OU makes considerable use of online provision. Students use a virtual learning environment (VLE) which provides access to course content (e.g. weekly study material, interactive quizzes, podcasts) and supports student interaction with peers and tutors using asynchronous (i.e. online forums) and synchronous (i.e. using messenger and video chat via Adobe Connect) communication methods. With changes in education policy (e.g. the recent Teaching and Excellence Framework in the UK) and the need to ensure employability skills, such as teamwork competencies and collaboration skills, are developed, teaching and learning in HE is changing. Traditional methods of instruction, such as one-way transmission of knowledge from teacher to student, are being replaced by active learning through interacting with fellow students. This has led to an increased prevalence of social and collaborative activities being incorporated into online learning programmes (Järvelä et al., 2015). At the OU, for instance, learning and assessment activities which encourage interaction and collaboration are being increasingly advocated (Evans \& Galley, 2016; Rienties \& Toetenel, 2016). The integration of such collaborative activities (either in assessed or non-assessed formats) into the Supported Open Learning model at the OU does, however, pose challenges. For example, due to the shared discussion, planning and creation often involved in collaborative learning, students may feel that their study flexibility has been reduced. It has also been found that some students may experience increased levels of unpleasant emotions, such as anxiety and frustration, when working collaboratively online (Donelan \& Kear, 2018; Hilliard, 2017) and are less satisfied with social learning activities when compared to other approaches to teaching and learning (Rienties \& Toetenel, 2016).

Over the last two decades, the importance of emotions in academic learning has been evidenced. Research has shown that emotions play a vital role in student motivation, selfregulation and academic achievement (Rienties \& Rivers, 2014). Although much research has focussed on the impact of emotions in face-to-face learning contexts, more evidence is being found for the importance of understanding emotions in online learning settings (e.g. Artino, 2012; Marchand \& Gutierrez, 2012). Much of this work has concentrated on individual learning situations, with less attention being paid to the social and collaborative elements of online learning. In a recent study, Reis et al. (2018) reviewed existing literature to explore the emotions reported during online collaborative learning. Results revealed both pleasant (e.g. surprise, joy, excitement) and unpleasant (e.g. frustration, anxiety, anger) emotions amongst the most frequently mentioned. As well as limited exploration of emotions in online collaborative settings, there is currently little research exploring the emotions of distance learners. The emotional experiences of these students may be impacted by the additional commitments many of them have, such as being in full-time or part-time employment. Gaining a greater insight into the emotional experiences of distance learners undertaking assessed, online, collaborative activities will be of great value to educators and institutions who have adopted, or who are planning to adopt this pedagogical approach. Findings may 
help with the design of future collaborative activities and support strategies for students who may experience unpleasant emotions.

\section{Purpose and Research Questions}

The main purpose of the study reported in this paper was to explore undergraduate distance learners' emotional experiences in an assessed, online, collaborative project. The following research questions were addressed:

- What emotions do learners self-report before, during and after an assessed, online, collaborative project?

- What are the perceived reasons for the self-reported emotions before, during and after an assessed, online, collaborative project?

\section{Study Context}

The study was undertaken using students from OU who were studying an undergraduate physics and astronomy module. As part of the module, students were required to work in teams to undertake a group project based around the modelling processes of the Earth's atmosphere. Students worked in teams of up to ten, sub-divided into three smaller specialist teams - one team undertook experiments, one mathematical modelling and one a literature survey (see Figure 1). After completing their tasks in the specialist teams, students combined results to produce the core of a scientific report (results and discussion sections). Students were individually required to produce the remaining sections of the report (abstract, introduction, and conclusion). Collaboration within the main team and specialist teams was expected throughout the duration of the 8-week team project. A student's overall grade for the project was made up of both individual ( $75 \%$ of overall grade) and group marks (25\% of overall grade) (see Figure 1).
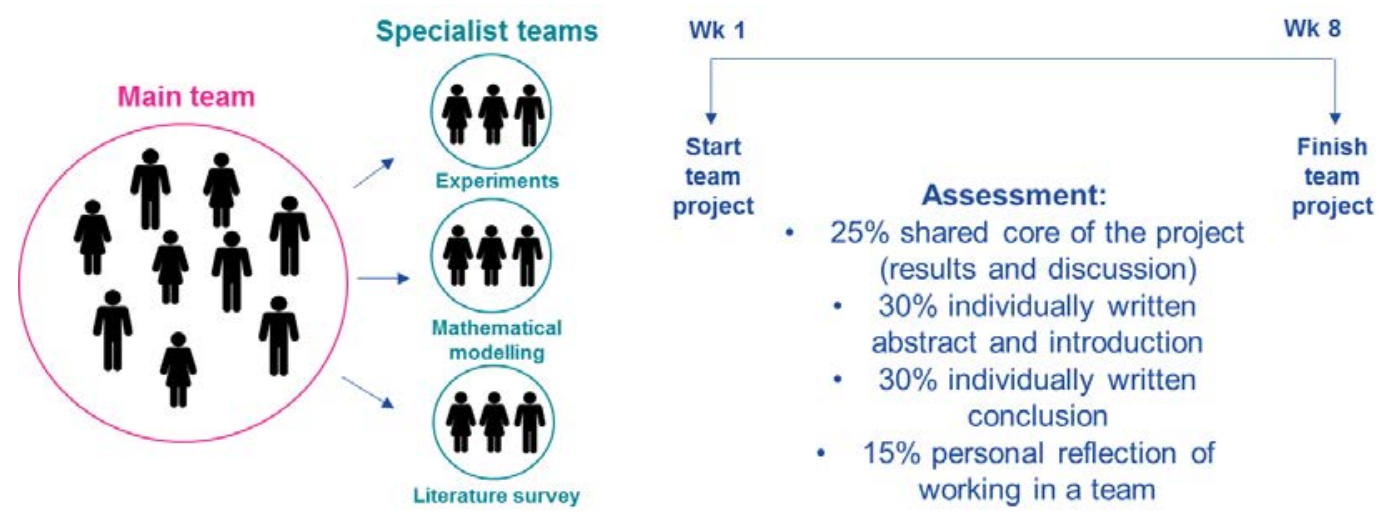

Figure 1. An overview of the assessed collaborative group project

\section{Methods}

\section{Sample and Procedures}

Seventeen students volunteered to participate (13 males and 4 females). The age of participants varied: 3 were aged under 25 years; 4 were aged between 26 - 35 years; 6 were 
aged between 36 - 45 years; and 3 aged were aged 56 years and over. One participant withdrew from the study 2 weeks into the collaborative project due to personal reasons (male, aged between $36-45$ years).

Before contacting students about taking part in this diary-based study, ethical approval was gained from The Open University's Human Research Ethics Committee (HREC) and Student Research Project Panel (SRPP). Invitation emails stating the purpose of the study, and informing students that taking part would have no effect on any aspect of their module or university study, were sent to 83 of the 158 students that studied the module that year. Some students could not be included because of rules observed by SRPP. Over a 9-week period, students were sent a link to six online diary entries (created using JISC Online Surveys). The first entry was to be completed before the start of the collaborative project, the next four during the project and the final entry after the project had been completed. Students were briefly instructed on how to fill out the diary entries after agreeing to take part in the study. Students had 48 hours to complete each diary entry; after this time, they were unable to access the online form. In total, 93 diary entries were completed out of a possible $102(91.2 \%$ completion rate). Four uncompleted diary entries were due to the one participated withdrawing from the study, whilst the remaining five were due to participants not completing the entry on time. For participating in the study, participants who completed four or more entries received a $£ 20$ Amazon voucher.

\section{Measures}

Diary methods have been used previously to explore student experiences of emotion in various learning contexts (e.g. Peterson, Brown, \& Jun, 2015; Zembylas, 2008). This method has many advantages, such as being able to explore temporal variations in emotions and minimising the retrospective bias that can be caused when using other data collection methods (Becker, Keller, Goetz, Frenzel, \& Taxer, 2015). Each of the six diary entries were structured, asking questions about the types of emotions experienced during a specific time period and their causes. Both quantitative and qualitative data were gathered.

\section{Type of emotion}

Students were asked to select (by ticking a check box) which emotions they had experienced in relation to the online collaborative project for the specific time period stated in each diary entry (e.g. the time since the previous diary entry). Students could select from six pleasant (enjoyment, excitement, pride, satisfaction, relief, hope) and eight unpleasant (boredom, frustration, disappointment, anxiety, anger, embarrassment, dissatisfaction, confusion) emotions. These emotions were selected based on previous research which has investigated emotions in online collaborative activities, face-to-face collaboration, and individual online learning settings. An "other" option was also provided so that students could identify any other emotions they had experienced. Additionally, a question at the end of each diary entry asked students to select the most dominant emotion they had experienced for the specific time period (from the fourteen previously stated emotions or an "other" option). 


\section{Cause of emotion}

If students identified that they had experienced one or more pleasant emotions, they were asked to explain (in an open-ended text box) the cause of one of these emotions for a specific occasion. This was repeated for unpleasant emotions.

\section{Analysis}

Quantitative data relating to the type of emotions experienced by students in relation the online collaborative project were analysed using descriptive statistics. Frequencies $(n)$ and percentages (\%) were calculated and transformed into tables in Microsoft Excel 2013. Qualitative data for the causes of emotions were analysed using classical content analysis (Leech \& Onwuegbuzie, 2008), using an inductive approach. This approach initially involved reading and re-reading the qualitative data to become familiar with the content. Data were then systematically worked through and interesting features coded. Codes were then grouped into higher level categories and these were quantified by counting the number of instances they were used in the text.

\section{Results}

\section{Types of emotions}

Frequencies and percentages of emotions reported during each of the six diary entries are reported in Table 1. Overall, slightly more pleasant emotions were reported over the six entries than unpleasant emotions (pleasant: 53.5\%; unpleasant: 46.5\%). More pleasant emotions than unpleasant emotions were reported in diary entries 1, 2 and 6, whereas more unpleasant emotions were reported in diary entries 3, 4 and 5. The total number of reported emotions was highest in diary entry 3 and lowest in diary entry 2. Of the six pleasant emotions, satisfaction and relief were reported most overall. Both of these emotions were reported by a large proportion of students in diary entries 5 and 6 . Satisfaction was also highly reported during diary entry 3. Hope and excitement were more frequently reported in entries 1 and 2 than in any of the other four entries. Apart from pride in entry 6, both enjoyment and pride were reported less frequently than other pleasant emotions. In addition to the eight unpleasant emotions listed, three further unpleasant emotions were reported by students (trepidation, unconfident, sadness). Of these eleven unpleasant emotions, anxiety and frustration were reported most overall. Anxiety was the most reported emotion during diary entry 1 and was highly reported during diary entry 3. Frustration was most reported during diary entry 5 and was also the most highly reported unpleasant emotion in diary entries 3 and 4. Other unpleasant emotions were less frequently reported.

Analysis of the most dominant emotion self-reported by participants in each entry (results table not reported), revealed that anxiety was the most reported emotion. This emotion was heavily reported in diary entry 1 . The second most self-reported dominant emotion was satisfaction. This was reported most frequent in diary entries 3 and 4. 
Exploring the Emotions of Distance Learning Students in an Assessed, Online, Collaborative Project Jake Hilliard et al.

Table 1: $\quad$ Self-reported pleasant and unpleasant emotions before, during and after the online collaborative project

\begin{tabular}{|c|c|c|c|c|c|c|c|c|c|c|c|c|c|c|}
\hline \multirow[t]{2}{*}{ Emotion } & \multicolumn{2}{|c|}{$\begin{array}{c}\text { Diary } 1 \\
\text { (before) }\end{array}$} & \multicolumn{2}{|c|}{$\begin{array}{c}\text { Diary } 2 \\
\text { (during) }\end{array}$} & \multicolumn{2}{|c|}{$\begin{array}{c}\text { Diary } 3 \\
\text { (during) }\end{array}$} & \multicolumn{2}{|c|}{$\begin{array}{c}\text { Diary } 4 \\
\text { (during) }\end{array}$} & \multicolumn{2}{|c|}{$\begin{array}{c}\text { Diary } 5 \\
\text { (during) }\end{array}$} & \multicolumn{2}{|c|}{$\begin{array}{c}\text { Diary } 6 \\
\text { (after) }\end{array}$} & \multicolumn{2}{|c|}{ Overall } \\
\hline & $n$ & $\%$ & $n$ & $\%$ & $n$ & $\%$ & $n$ & $\%$ & $n$ & $\%$ & $n$ & $\%$ & $n$ & $\%$ \\
\hline Pleasant & 22 & 61.1 & 19 & 61.3 & 28 & 48.3 & 21 & 45.7 & 23 & 42.6 & 25 & 75.8 & 138 & 53.5 \\
\hline Satisfaction & 3 & 8.3 & 5 & 16.1 & 8 & 13.8 & 5 & 10.9 & 8 & 14.8 & 8 & 24.2 & 37 & 14.4 \\
\hline Relief & 5 & 13.9 & 2 & 6.5 & 6 & 10.3 & 5 & 10.9 & 8 & 14.8 & 11 & 33.3 & 37 & 14.4 \\
\hline Hope & 4 & 11.1 & 5 & 16.1 & 5 & 8.6 & 4 & 8.7 & 3 & 5.6 & 1 & 3.0 & 22 & 8.5 \\
\hline Excitement & 6 & 16.7 & 4 & 12.9 & 4 & 6.9 & 3 & 6.5 & 2 & 3.7 & 1 & 3.0 & 20 & 7.8 \\
\hline Enjoyment & 3 & 8.3 & 2 & 6.5 & 3 & 5.2 & 3 & 6.5 & 1 & 1.9 & 1 & 3.0 & 13 & 5.0 \\
\hline Pride & 1 & 2.8 & 1 & 3.2 & 2 & 3.4 & 1 & 2.2 & 1 & 1.9 & 3 & 9.1 & 9 & 3.5 \\
\hline Unpleasant & 14 & 38.9 & 12 & 38.7 & 30 & 51.7 & 25 & 54.3 & 31 & 57.4 & 8 & 24.2 & 120 & 46.5 \\
\hline Anxiety & 9 & 25.0 & 4 & 12.9 & 7 & 12.1 & 5 & 10.9 & 5 & 9.3 & 2 & 6.1 & 32 & 12.4 \\
\hline Frustration & 1 & 2.8 & 3 & 9.7 & 8 & 13.8 & 6 & 13.0 & 10 & 18.5 & 1 & 3.0 & 29 & 11.2 \\
\hline Dissatisfaction & 1 & 2.8 & 2 & 6.5 & 4 & 6.9 & 2 & 4.3 & 5 & 9.3 & 3 & 9.1 & 17 & 6.6 \\
\hline Disappointment & 0 & 0.0 & 1 & 3,2 & 4 & 6.9 & 4 & 8.7 & 3 & 5.6 & 1 & 3.0 & 13 & 5.0 \\
\hline Confusion & 0 & 0.0 & 0 & 0.0 & 3 & 5.2 & 3 & 6.5 & 2 & 3.7 & 1 & 3.0 & 9 & 3.5 \\
\hline Anger & 0 & 0.0 & 1 & 3,2 & 0 & 0.0 & 2 & 4.3 & 3 & 5.6 & 0 & 0.0 & 6 & 2.3 \\
\hline Embarrassment & 1 & 2.8 & 0 & 0.0 & 2 & 3.4 & 1 & 2.2 & 2 & 3.7 & 0 & 0.0 & 6 & 2.3 \\
\hline Boredom & 1 & 2.8 & 1 & 3.2 & 2 & 3.4 & 1 & 2.2 & 0 & 0.0 & 0 & 0.0 & 5 & 1.9 \\
\hline Trepidation & 1 & 2.8 & 0 & 0.0 & 0 & 0.0 & 0 & 0.0 & 0 & 0.0 & 0 & 0.0 & 1 & 0.4 \\
\hline Unconfident & 0 & 0.0 & 0 & 0.0 & 0 & 0.0 & 1 & 2.2 & 0 & 0.0 & 0 & 0.0 & 1 & 0.4 \\
\hline Sadness & 0 & 0.0 & 0 & 0.0 & 0 & 0.0 & 0 & 0.0 & 1 & 1.9 & 0 & 0.0 & 1 & 0.4 \\
\hline Total & 36 & 100 & 31 & 100 & 58 & 100 & 46 & 100 & 54 & 100 & 33 & 100 & 258 & 100 \\
\hline
\end{tabular}

\section{Reasons for emotions}

Approximately 119 answers were provided when students were asked to describe the cause of emotions experienced in the online collaborative project. Seventy of these were for occasions when participants had experienced a specific pleasant emotion and 49 were related to specific unpleasant emotions. As more than one cause may have been stated in each response, a total of 141 descriptions of the causes of emotions were found. After initial analysis, 13 categories for the causes of emotions were identified. These were (frequencies provided in brackets): completion of project or module (24); participation and engagement from others (18); task progress (18); working and collaborating with others (17); performance in the project or module (15); self-belief (15); the task itself (11); guidance and support (8); workload and assessment timing (7); time availability (3); technology and software (2); external factors (2); and other (1).

\section{Pleasant emotions}

All causes in the completion of project or module category were related to pleasant emotions (24 out of 24). Many of these related to the relief and satisfaction of completing the project, whilst other answers related to the anticipation of finishing the project and ultimately the module. The majority of causes in the task progress category were also related to pleasant emotions (15 out of 18). These included both individual and group progress that had been made in the project. A number of pleasant emotions were caused by working and collaborating with others (10 out of 17). Reasons varied from the general enjoyment of meeting and working with others to the positive social interactions between group members. For instance, one student stated student "I enjoyed collaborating as part of the modelling team". Participation and engagement from others also led to a number of pleasant emotions (9 out of 18). This category referred to the participation and engagement of other students in the 
task. For instance, one student wrote "Relief that the rest of my group also seems motivated to get the project completed". Aspects of the task itself also caused a number of pleasant emotions (7 out of 11). For example, one student was satisfied because the project resembled a "real world" investigation and enjoyed being able to undertake a "massive group project". From the remaining six categories, only one pleasant emotion was related to the self-belief category and there were no pleasant emotions from the remaining five categories.

\section{Unpleasant emotions}

Many unpleasant emotions stemmed from the self-belief category (14 out of 15). Reasons for these emotions predominantly related to having self-doubts about their own ability, or thoughts of letting themselves or others down in the project. These responses mainly occurred in diary entries 1 and 2 and were often related to feelings of anxiety. A number of unpleasant emotions were caused by participation and engagement from others (9 out of 18). These often related to other students not communicating or participating in the activity and were often linked to frustration, disappointment and anxiety. Performance in the project or module ( 8 out of 15) was another cause of unpleasant emotion. Many reasons related to the final quality of the report for the project. A lack of guidance and support (8 out of 8) predominantly from the course content and tutor were a source of unpleasant emotion for some learners. For example, a student wrote "Lack of instruction about what needs to be done from OU". These responses were often linked to frustration and confusion. Categories of working and collaborating with others ( 7 out of 17) and workload and assessment timing (7 out of 7) were also commonly cited reasons for unpleasant emotions. Fewer unpleasant emotions stemmed from the remaining six categories. From these, unpleasant emotions related to time availability category ( 3 out of 3 ) stemmed from not having enough time to complete the project. For instance, one student stated that they felt anxious "... about being able to find the time required to do the necessary work". The difficulty of the task was found to be a reason for unpleasant emotion for the task itself category (4 out of 11). Technology and software caused a small number of unpleasant emotions during the project (2 out of 2 ).

\section{Conclusion}

Findings revealed that learners experienced a range of pleasant and unpleasant emotions in relation to the assessed, online, collaborative project. The use of qualitative data also allowed for numerous reasons for emotions to be identified. There are a number of implications for educators and learning designers from these findings. Firstly, before the activity began anxiety was by far the most commonly reported emotion, often resulting from low self-belief and the fear of lettings others down. The use of prior activities aimed at increasing confidence and trust in learners when interacting and collaborating online is one way that may help reduce these unpleasant feelings. Secondly, it was reported that a lack of guidance and support during the project resulted in frustration and confusion. Ensuring activity guidelines are clear and that support can be gained when needed (e.g. from tutors), will hopefully help create a more positive learning environment. Thirdly, the "real world" value and ability to use skills learnt previously in the module were stated as reasons for pleasant emotions by students. This 
finding highlights the importance of task value and authenticity when designing assessed, online, collaborative activities.

The use of a structured online diary proved to be an effective way of gathering data about student emotion during an assessed, online collaborative project. When compared to other data collection methods more commonly used to explore student emotions (e.g. surveys, interviews), diaries allowed for a reduced recall period helping to overcome issues of memory decay and retrospective bias which are often associated with these other methods. Being able to explore emotions and their causes at multiple time points also allowed for temporal variations and within person changes to be explored. One concern that researchers may have when using an online diary is the potential for large dropout rates or an increased number of incomplete entries. However, in this study we observed a small dropout rate (one student due to personal reasons) and a high diary entry completion rate (91.2\%).

\section{References}

Artino, A. (2012). Emotions in online learning environments: Introduction to the special issue. The Internet and Higher Education, 15(3), 137-140.

Becker, E. S., Keller, M. M., Goetz, T., Frenzel, A. C., \& Taxer, J. L. (2015). Antecedents of teachers' emotions in the classroom: an intraindividual approach. Frontiers in Psychology, 6(635).

Donelan, H., \& Kear, K. (2018). Creating and collaborating: students' and tutors' perceptions of an online group project. International Review of Research in Open and Distributed Learning, 19(2).

Evans, G., \& Galley, R. (2016). Collaborative online activities: a guide to good practice. Milton Keynes: The Open University.

Higher Education Student Statistics (2019). Who's studying in HE?: Personal characteristics. Retrieved January 30, 2019, from https://www.hesa.ac.uk/data-andanalysis/students/whos-in-he/characteristics

Hilliard, J. (2017). Students' Perceptions and Experiences of Anxiety in an Online Collaborative Project. The Open University.

Järvelä, S., Kirschner, P. A., Panadero, E., Malmberg, J., Phielix, C., Jaspers, J., Koivuniemi, M., \& Järvenoja, H. (2015). Enhancing socially shared regulation in collaborative learning groups: Designing for CSCL regulation tools. Educational Technology Research and Development, 63(1), 125-142.

Leech, N. L., \& Onwuegbuzie, A. J. (2008). Qualitative data analysis: A compendium of techniques and a framework for selection for school psychology research and beyond. Psychological Association, 23(4), 587-604.

Marchand, G. C., \& Gutierrez, A. P. (2012). The role of emotion in the learning process: Comparisons between online and face-to-face learning settings. The Internet and Higher Education, 15(3), 150-160. 
Peterson, E. R., Brown, G. T. L., \& Jun, M. C. (2015). Achievement emotions in higher education: A diary study exploring emotions across an assessment event. Contemporary Educational Psychology, 42(1), 82-96.

Reis, R. C. D., Isotani, S., Rodriguez, C. L., Lyra, K. T., Jaques, P. A., \& Bittencourt, I. I. (2018). Affective states in computer-supported collaborative learning: Studying the past to drive the future. Computers \& Education, 120, 29-50.

Rienties, B., \& Rivers, B. (2014). Measuring and understanding learner emotions: Evidence and prospects. Learning Analytics Community Exchange (LACE).

Rienties, B., \& Toetenel, L. (2016). The impact of 151 learning designs on student satisfaction and performance: social learning (analytics) matters. Proceedings of the Sixth International Conference on Learning Analytics \& Knowledge - LAK '16, 339-343.

The Open University (2018). Strategy and policies: Facts and figures. Retrieved January 30, 2019, from http://www.open.ac.uk/about/main/strategy-and-policies/facts-and-figures

Zembylas, M. (2008). Adult learners' emotions in online learning. Distance Education, 29(1), 71-87. 